\title{
Simulation tests of the cutting force in the process of machining of ruled surfaces with a conical end mill
}

\author{
Badania symulacyjne siły skrawania \\ w procesie obróbki powierzchni prostokreślnych frezem stożkowym
}

\author{
JAN BUREK \\ KAROL ŻURAWSKI \\ PIOTR ŻUREK *
}

The analysis of the cutting force in the flank milling process with a conical mill is presented in this article. The tests were carried out for various twist angles of the machined surface and different values of the lead angle.

KEYWORDS: five-axis milling, conical ball nose mill, ruled surface, cutting force

Five-axis milling technologies are now used to produce geometrically complex parts for the aerospace industry, such as turbine blades and rotors, and compressors. However, processing such complex elements is still a technologica problem. On the one hand, this results from the required dimensional and shape accuracy as well as high surface quality, on the other hand - from the desire to maximize the efficiency of the process $[6-8,10]$.

Most often machining of complex surfaces is used in the rounding with the ball nose end mill strategy. It allows to make surfaces of any shape. The disadvantage of this strategy is that it has very low efficiency. In the case of machining of ruled surfaces, it is possible to use conical tool for flank milling (fig. 1) and obtain much higher machining efficiency compared to the possibilities offered by common strategy $[8,10]$.

a)

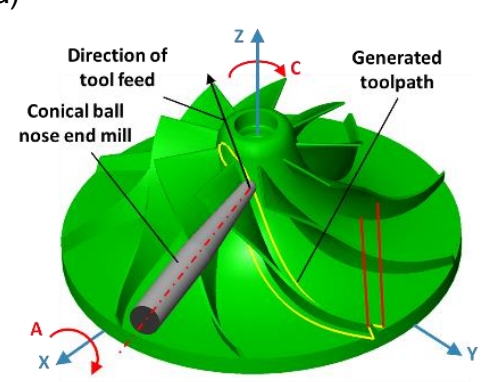

b)

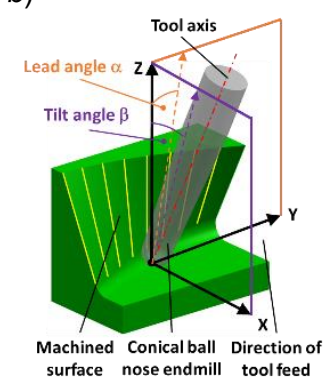

Fig. 1. Scheme: a) flank milling of the rotor, b) five-axis positioning parameters of the tool axis $[6,7]$

* Dr hab. inż. Jan Burek prof. PRz (jburek@prz.edu.pl), mgr inż. Karol Żurawski (zurawski@prz.edu.pl), mgr inż. Piotr Żurek (p_zurek@prz.edu.pl) - Katedra Technik Wytwarzania i Automatyzacji Politechniki Rzeszowskiej
This method allows to achieve much greater efficiency, but when machining non-developable ruled surfaces, there is a risk of undercuts or leftover machining allowance due to the linear contact of the tool with the workpiece (fig. 2).

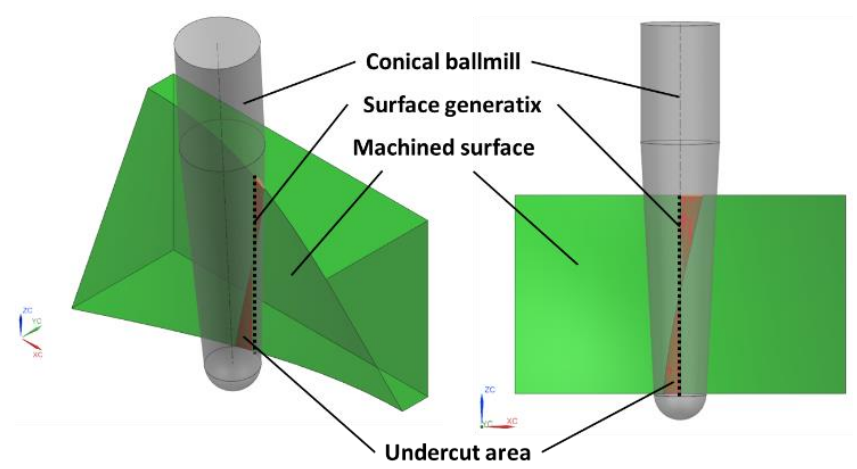

Fig. 2. Scheme of undercuts forming during machining of a non-developable ruled surface $[6,7]$
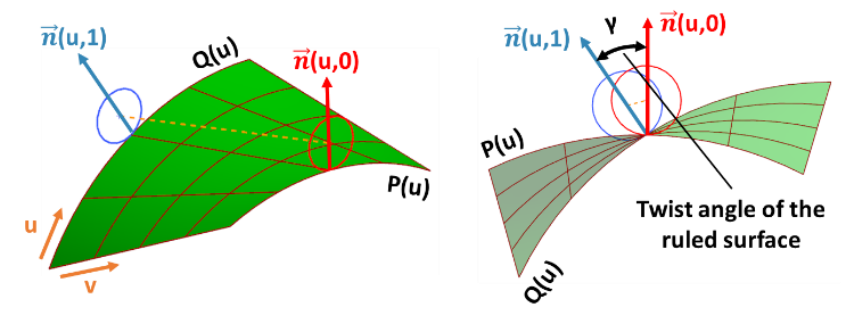

Fig. 3. Twist angle $y$ of the non-developable ruled surface [6, 7]

In order to reduce this phenomenon, it is necessary to change the lead angle $\alpha$ continuously during machining, depending on the change in the angle of rotation $y$ of the work surface (fig. 3) [5, 6].

The change of the lead angle $\alpha$ and the twist angle $\gamma$ changes the surface area of the cutting layer and the length of the active cutting edge, which directly affects the values of the cutting force (fig. 4), described by the mechanistic model $[1-3,5,9]$ : 


$$
\left\{\begin{array}{l}
d F_{\mathrm{t}}=K_{\mathrm{te}} d S+K_{\mathrm{tc}} d A \\
d F_{\mathrm{r}}=K_{\mathrm{re}} d S+K_{\mathrm{rc}} d A \\
d F_{\mathrm{a}}=K_{\mathrm{ae}} d S+K_{\mathrm{ac}} d A
\end{array}\right.
$$

where:

$F_{\mathrm{t}}$ - tangential component of the cutting force,

$F_{\mathrm{r}}$ - radial component of the cutting force,

$F_{\mathrm{a}}$ - axial component of the cutting force,

$S$ - active length of the cutting edge,

$A$ - cross-sectional area of the cutting layer,

$K_{\mathrm{te}}, K_{\mathrm{re}}, K_{\mathrm{ae}}$ - edge proportionality factors affecting the cutting edge, determined experimentally,

$K_{\mathrm{tc}}, K_{\mathrm{rc}}, K_{\mathrm{ac}}$ - proportionality factors related to shear, determined experimentally.

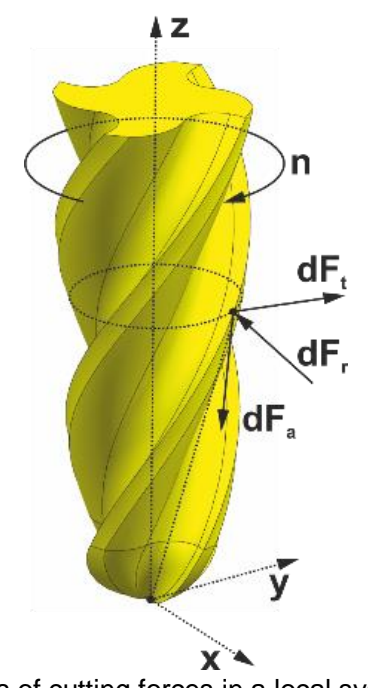

Fig. 4. Components of cutting forces in a local system [1-3]

The value and distribution of the cutting force has a direct effect on the deformation of the MGTW (machine - grip - toolworkpiece) system, which results in deviations in shape $[1-3,5,9]$.

The purpose of this work was to determine the influence of the lead angle $\alpha$ and the twist angle of the ruled surface $y$ on the values of the cutting force components in the process of five-axis flank milling.

\section{Simulation tests}

Boolean operations performed between the test model and the tool model were used for analysis. At the first stage, a test model was prepared in the NX 11. It contained ruled surfaces with different values of the twisting angle $\gamma$.

The finished element was imported into the hyperMill environment in which machining was programmed with different tooling angles $\alpha$ and the indirect data was generated.

The next step was to create a pattern of a previously prepared tool model based on indirect data. In addition, in each subsequent repetition, the tool model rotated at the angle resulting from the specified feed per tooth.

The final stage was to subtract the generated models from the test body. This operation allowed to determine the crosssectional area of the cutting layer and the effective cutting edge length (fig. 5).

The obtained values were used in mechanistic formulas to determine the values of the cutting force components. The technological parameters and coefficients values used in the simulation are presented in the table I and II.

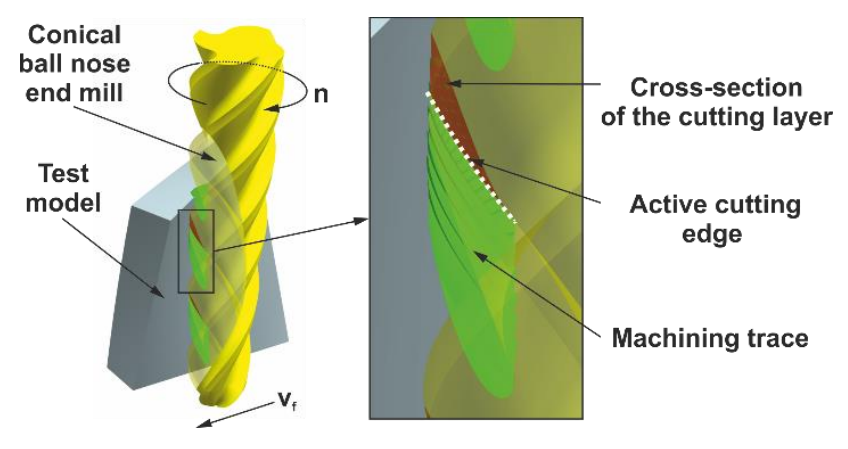

Fig. 5. Method of determining the cross-section of the cutting layer and the effective length of the cutting edge

\section{TABLE I. Parameters adopted for the analysis}

\begin{tabular}{|l|c|}
\hline Tool diameter $d, \mathrm{~mm}$ & 6 \\
\hline Depth of cut $a_{\mathrm{p}}, \mathrm{mm}$ & 20 \\
\hline Width of cut $a_{e}, \mathrm{~mm}$ & 0,3 \\
\hline Feed per tooth $f_{z}, \mathrm{~mm} /$ tooth & 0,055 \\
\hline Range of lead angle $\alpha,^{\circ}$ & od -3 do +3 \\
\hline $\begin{array}{l}\text { Range of twist angle of the machined } \\
\text { surface } \gamma,{ }^{\circ}\end{array}$ & od 0 do 30 \\
\hline
\end{tabular}

TABLE II. Proportionality coefficients for Ti6AI4V $[1,4]$

\begin{tabular}{|l|c|}
\hline$K_{\mathrm{tc}}, \mathrm{N} / \mathrm{mm}^{2}$ & 2172,1 \\
\hline$K_{\mathrm{rc}}, \mathrm{N} / \mathrm{mm}^{2}$ & 848,9 \\
\hline$K_{\mathrm{ac}}, \mathrm{N} / \mathrm{mm}^{2}$ & $-725,07$ \\
\hline$K_{\mathrm{te}}, \mathrm{N} / \mathrm{mm}^{2}$ & 17,29 \\
\hline$K_{\mathrm{re}}, \mathrm{N} / \mathrm{mm}$ & 7,79 \\
\hline$K_{\mathrm{ae}}, \mathrm{N} / \mathrm{mm}$ & $-6,63$ \\
\hline
\end{tabular}

\section{Analysis of results}

Figs. 6-14 show the dependences of the values of the cutting forces $F_{\mathrm{t}}, F_{\mathrm{r}}, F_{\mathrm{a}}$ for different lead angles $\alpha$ and twist angles of the ruled surface $\gamma$ as a function of the rotation angle of the tool $\varphi$. On the basis of the analysis of the graphs of the cutting forces $F_{\mathrm{t}}, F_{\mathrm{r}}, F_{\mathrm{a}}$, one can notice the significant influence of both the lead angle $\alpha$ and the twist angle of ruled surface $y$.

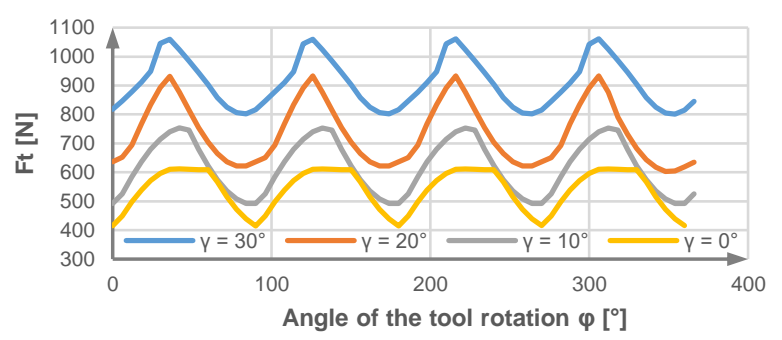

Fig. 6. Tangential component of the cutting force $F_{\mathrm{t}}$ as a function of the tool rotation angle for the lead angle $\alpha=+3^{\circ}$

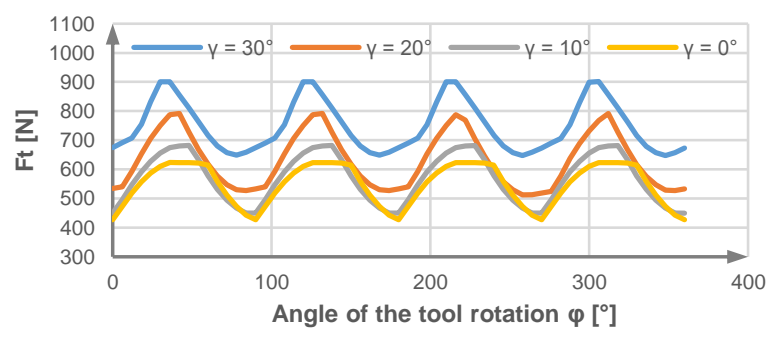

Fig. 7. Tangential component of the cutting force $F_{\mathrm{t}}$ as a function of the tool rotation angle for the lead angle $\alpha=0^{\circ}$ 




Fig. 8. Tangential component of the cutting force $F_{\mathrm{t}}$ as a function of the tool rotation angle for the lead angle $\alpha=-3^{\circ}$

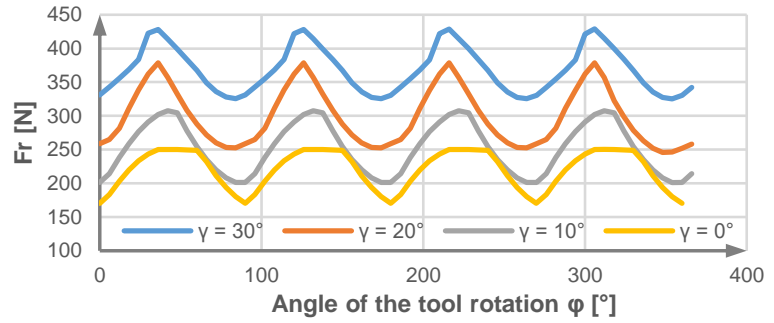

Fig. 9. Radial component of the cutting force $F_{\mathrm{r}}$ as a function of the tool rotation angle for the lead angle $\alpha=+3^{\circ}$

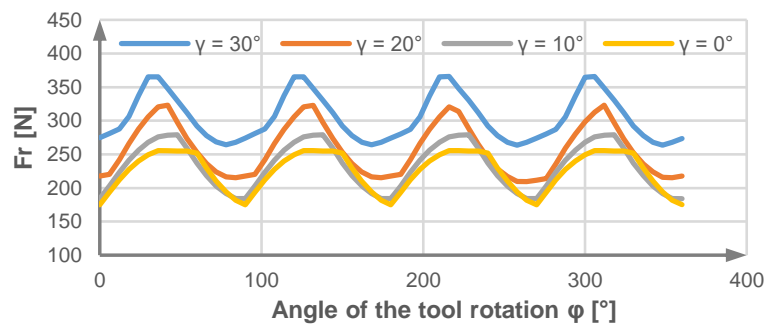

Fig. 10. Radial component of the cutting force $F_{\mathrm{r}}$ as a function of the tool rotation angle for the lead angle $\alpha=0^{\circ}$

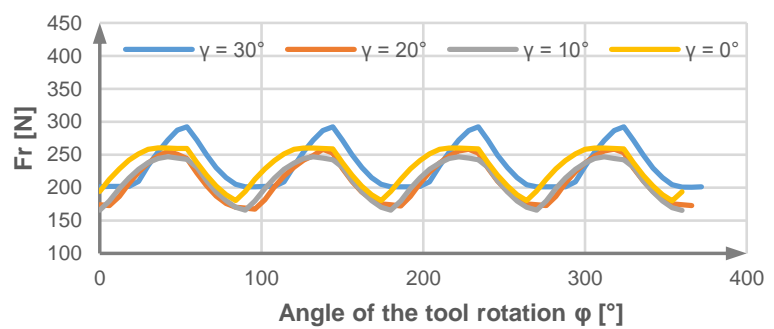

Fig. 11. Radial component of the cutting force $F_{\mathrm{r}}$ as a function of the tool rotation angle for the lead angle $\alpha=-3^{\circ}$

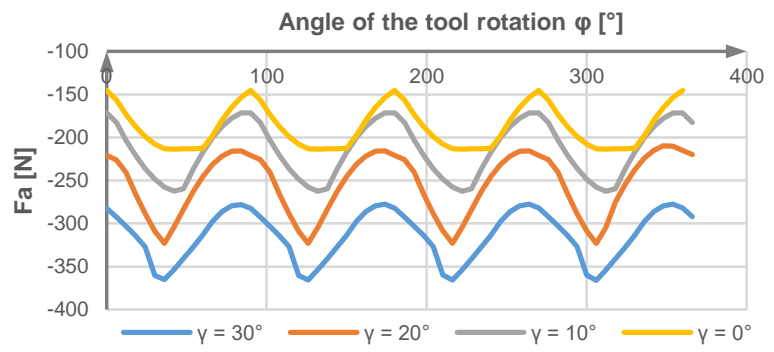

Fig. 12. Axial component of the cutting force $F_{\mathrm{a}}$ as a function of the tool rotation angle for the lead angle $\alpha=+3^{\circ}$

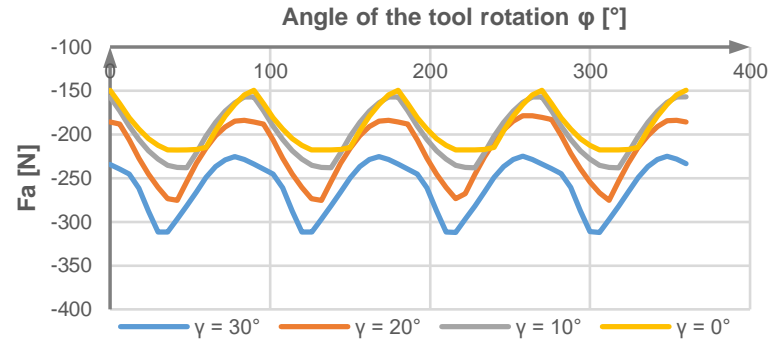

Fig. 13. Axial component of the cutting force $F_{\mathrm{a}}$ as a function of the tool rotation angle for the lead angle $\alpha=0^{\circ}$

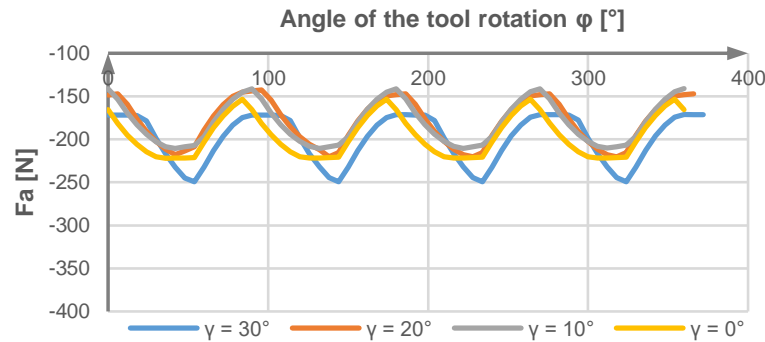

Fig. 14. Axial component of the cutting force $F_{\mathrm{a}}$ as a function of the tool rotation angle for the lead angle $\alpha=-3^{\circ}$

In the case of using the zero lead angle $\alpha$, the component values of the cutting force increased with the increase of the value of the twist angle of the surface $\gamma$. The maximum values of the force components were achieved for $y=30^{\circ}$. With reference to the values obtained at $y=0^{\circ}$, this increase reached $40 \%$.

In the case of the lead angle $\alpha=3^{\circ}$, the values of the components of the cutting force also increased with the increase in the value of the twist angle of the surface $\gamma$. Analogously to the angle $\alpha=0^{\circ}$, the maximum value was obtained for $y=30^{\circ}$. In relation to the values recorded at $y=0^{\circ}$, the increase was even up to $70 \%$.

The application of the lead angle $\alpha=-3^{\circ}$ with reference to the values of the cutting forces for $y=0^{\circ}$ resulted in:

- for $y=30^{\circ}$ - a small increase in $F_{\mathrm{t}}, F_{\mathrm{r}}, F_{\mathrm{a}}(10 \%)$,

- for $y=20^{\circ}$ - maintaining the $F_{\mathrm{t}}, F_{\mathrm{r}}, F_{\mathrm{a}}$ values at a comparable level,

- for $y=10^{\circ}$ - slight decrease in $F_{\mathrm{t}}, F_{\mathrm{r}}, F_{\mathrm{a}}$ (around $5 \%$ ).

\section{Conclusions}

On the basis of simulation tests, it can be stated that in the process of five-axis peripheral milling the values of the angle of cut $\alpha$ and the angle of twisting of the ruled surface $y$ have a significant impact on the values of the cutting force.

The use of a zero or positive lead angle $\alpha$ resulted in undercuts in the machined surface. As a consequence, this led to an increase in the cross-sectional area of the cutting layer with the increase of the twisting angle $\gamma$, and as a result also to the increase in the values of the cutting forces $F_{\mathrm{t}}, F_{\mathrm{r}}$, $F_{\text {a. }}$.

On the other hand, the use of a negative angle $\alpha$ caused a decrease in the cross-sectional area of the cutting layer, which allowed to significantly reduce the differences in the values of the cutting forces in the considered range of $y$ angles.

In order to minimize the impact of deformations of the MGTW system on the accuracy of the machined surface, it is necessary to continuously change the angle of conduct $\alpha$ depending on the change in the angle of twisting $\gamma$ of the rectangular area. 


\section{REFERENCES}

1. Altinas Y., Lee P. "Prediction of ball-end milling forces from orthogonal cutting data". The International Journal of Advanced Manufacturing Technology. 36, 9 (1996): pp. 1059-1072.

2. Altinas Y., Lee P. "Mechanics and dynamics of ball end milling". Transaction of ASME, Journal of Manufacturing Science and Engineering. 120 (1998): pp. 684-692.

3. Altinas Y., Engin S. "Generalized modeling of milling mechanics and dynamics: part I - helical end mills". CIRP Annals. 50 (2001): pp. 25-30.

4. Altinas Y., Armarego E.J.A., Budak E. "Prediction of milling force coefficient from orthogonal cutting data". Transaction of ASME. 118 (1996): pp. 216-224.

5. Artetxe E., Urbikain G., Lamikiz A., López de Lacalle L.N., González R., Rodal P. "A Mechanistic Cutting Force Model for New Barrel End Mills". Procedia Engineering. 132 (2015): pp. 553560.

6. Burek J., Żurawski K., Żurek P. „Wpływ kąta prowadzenia frezu na dokładność wymiarowo-kształtową powierzchni prostokreślnych". Mechanik. 87, 8-9 (2014): p. 729.

7. Burek J., Żurawski K., Żurek P. „Wpływ kąta pochylenia freza na dokładność kształtową powierzchni prostokreślnych". Mechanik. 89, 10 (2016): pp. 1472-1473.

8. Ferry W. "Virtual five-axis flank milling of jet engine impellers". Vancouver: The University of British Columbia, 2008.

9. Gorka U., Artetxe E., López de Lacalle L.N. "Numerical simulation of milling forces with barrel-shaped tools considering runout and tool inclination angles". Applied Mathematical Modelling. 47, (2017): pp. 619-636.

10. Waldt N. "NC-Programmierung für das funfachsige Flan-ken-frasen von Feriformflachen". Universitat Hannover, 2005.

Translation of scientific articles, their computer composition and publishing them on the website www.mechanik.media.pl by original articles in Polish is a task financed from the funds of the Ministry of Science and Higher Education designated for dissemination of science.

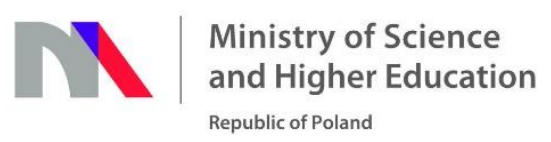

